\title{
IMPACT OF USABLE COEFFICIENT OF ADHESION BETWEEN TYRE AND ROAD SURFACE BY MODERN VEHICLE ON ITS DYNAMICS WHILE DRIVING AND BRAKING IN THE CURVE
}

\author{
Vladimír Panáček, Marek Semela, Vladimír Adamec, Barbora Schüllerová \\ Institute of Forensic Engineering, Brno University of Technology, Czech Republic
}

Submitted 7 July 2015; resubmitted 21 October 2015, 5 January 2016; accepted 14 January 2016

\begin{abstract}
The paper deals in detail with the analysis of driving and braking of the Volvo V40 T5 AWD Cross Country vehicle in the curve with radius 30, 40 and 50 meters laying emphasis on usable coefficient of adhesion values between tyre and road surface in the longitudinal and lateral direction. Individual dynamical driving and braking experiments in the curve were carried out using both modes of the Volvo stability system DSTC. We found out the range of values of coefficient of adhesion in the longitudinal and lateral direction depending on the vehicle speed and curve radius of the road. Experimentally determined values are utilised efficiently for the calculation of limit speed of a modern vehicle in the curve or, for instance, at the forensic reconstruction of a road accident.
\end{abstract}

Keywords: adhesion; vehicle; driving; braking; road surface; tyre; stability system.

\section{Introduction}

In today's production of modern vehicles great emphasis is put on the safety and operational efficiency, but also on driving comfort. These aspects lead to implementation of the so-called electronic assistance systems of the vehicle, which help the driver to control it. Among the supporting systems of the vehicle, as far as safety is concerned, among other things, there are also electronic stabilization systems of driving dynamics. This paper examines in detail the behaviour of the vehicle when driving and braking in a curve under the influence of electronic stabilization system of the chassis with respect to attainable parameters of vehicle driving dynamics.

\section{Background}

Burg and Moser (2009) present relations of lateral acceleration of the vehicle to speeds at different vehicle movement dynamics. There are obvious value ranges of lateral acceleration of the vehicle divided into five defined dynamic states (movements) of the vehicle. Under normal driving conditions utilized lateral acceleration ranged within the values of approximately 2 to $3.1 \mathrm{~m} / \mathrm{s}^{2}$, under fast driving in the range from 3.1 to $4.4 \mathrm{~m} / \mathrm{s}^{2}$, under sporty driving in the range of about 4.0 to $5.7 \mathrm{~m} / \mathrm{s}^{2}$, during a fierce passage in the range from 5.0 to $5.7 \mathrm{~m} / \mathrm{s}^{2}$. The values of lateral acceleration in the from 5.8 to $6.4 \mathrm{~m} / \mathrm{s}^{2}$ already represent a critical driving situation. For example, Zhu and Zhang (2012), devoted their time to coefficients of adhesion rate and the radius of curve depending on the traffic flow and it's modelling - both analytically and numerically. They presented a model describing the movement of vehicles travelling on a roadway in a curve. The stability condition was obtained using control theories. For verification, they performed simulations with a good match. Adhesion rates were chosen from the values of $0.2,0.4,0.6$ and 0.8 and the curve radius from 30,60, 90 and $120 \mathrm{~m}$, with the total track of $800 \mathrm{~m}$ and the simulation was performed using 200 vehicles. If the curve radius is constant, the safe speed of driving increases the same as the coefficient of adhesion rate, so that also the flow of vehicles is bigger. If the coefficient of adhesion rate is constant, the maximum flow of vehicles is higher on roads with a larger radius of the curve. Finally, it was determined that the amplitude of speed increases with an increase in the curve radius and the coefficient of adhesion rate. Already the study of Ritchie et al. (1968) found a relationship between the longitudinal velocity component and lateral acceleration when driving in a curve during normal driving, which was attended by 50 drivers in 227 bends. The results showed that the lateral acceleration was an inverse function of the speed in the curve, men were driving faster than women and therefore they use higher acceleration values. Dell'Acqua (2015) found that speed adopted by drivers is not consistent with road

Corresponding author: Barbora Schüllerová

E-mail: barbora.schullerova@usi.vutbr.cz 
alignment and imposed speed limit. The study of Wesemeier and Isermann (2009) is dedicated, among other things, to measurement of dynamic quantities and application on a single-track model when the vehicle passes through the curve. Several examples show possible approaches and results, e.g. with a $14 \mathrm{~m}$ radius of the curve the vehicle reached the speed of about $10 \mathrm{~m} / \mathrm{s}$ (i.e. $36 \mathrm{~km} / \mathrm{h}$ ) and the lateral acceleration in the range from 7.5 to $9 \mathrm{~m} / \mathrm{s}^{2}$. When driving slalom, they achieved the limit values of lateral acceleration again in the range of $8-10 \mathrm{~m} / \mathrm{s}^{2}$. Heinrichs et al. (2004) investigated the issue of sliding friction depending on the initial vehicle speed. Measured data showed values of the sliding friction coefficient when skidding from the speeds of $20,40,60$ and $80 \mathrm{~km} / \mathrm{h}$ when using three different types of tyres. Braking started from the initial speed to the moment the wheels got blocked. Blocking of the first wheel occurred at a time from 0.34 to $0.46 \mathrm{~s}$. The values of sliding friction with the wheels blocked decreased with an increasing speed, although the differences at speeds of 60 and $80 \mathrm{~km} / \mathrm{h}$ were not statistically significant. With sliding friction, the values reached from 0.72 to 0.80 for skidding tracks of $5 \mathrm{~m}$ above, with a short skidding track the values of sliding friction were higher, reaching the value up to 1.0. The paper presents sources, which, in the past, confirmed the nonlinear decrease of sliding friction values with an increasing speed. Commonly used values (in the paper) of sliding friction between 0.6 and 0.8 are, with respect to sliding friction studies, considered, at the initial speed of $20 \mathrm{~km} / \mathrm{h}$, as undervalued by $9-21 \%$. At higher driving speeds, there has been a generally possible used value of sliding friction of about 0.74 for the combination of all-wheel skidding opposed to previously published values from 0.55 to 0.70 at speeds over $50 \mathrm{~km} / \mathrm{h}$. Use of the previously accepted values of sliding friction would mean finding the initial speed of about $18 \%$ lower. For tyres of the 'touring' type the values were lower than for the types of 'economy' and 'performance.' Measured data from the above-mentioned paper, however, were obtained only for one Honda Accord vehicle made in 1991, without the ABS system and used sets of tyres for free. Methodology for detecting lateral forces applied on the tyre based on the so-called 'Kalman filter' was presented by Kim (2009) when parameters of the forces and skidding were compared during experiments and lateral acceleration of the vehicle reaching values from 9 to $10 \mathrm{~m} / \mathrm{s}^{2}$.

Rudin-Brown and Noy (2002) concluded that some drivers, equipped with a driving stability system, were risking more, which they called the behavioural adaptation. They explained that as a result of confidence in the stability system, and that was why they were very confident. The relation between use of the stabilization system and behavioural adaptation has not been examined well. Finally, it was pointed out that drivers who believed that their vehicle was equipped with a stabilization system underwent a greater degree of risk. It was most evident among young drivers and men.

\section{Experimental Section}

Within the scope of foreign internships of two of authors of this work, at the Technical University of Graz (Austria), at the testing DSD (Dr. Steffan Datentechnik, Linz, Austria) polygon within the area of the Austrian village of Allhaming they measured driving parameters of a very modern vehicle Volvo V40 T5 AWD Cross Country with an emphasis on detecting vehicle behaviour when driving and braking in a curve at faster speeds above $50 \mathrm{~km} / \mathrm{h}$.

\subsection{Tested Vehicle}

The object used for driving tests or determination of parameters of driving dynamics was a modern vehicle Volvo V40 T5 AWD Cross Country equipped with chassis stability assistance systems (ABS, ASR, DSTC). The tested vehicle was also equipped, among other things, with a powerful petrol engine with automatic transmission, All-Wheel Drive (AWD), and asymmetric tyres Pirelli PZERO 225/45 R18 95W with $8.0 \mathrm{~mm}$ tread depth in the main grooves on all wheels.

\subsection{Measuring Technology/Equipment}

For the purpose of determination of parameters of driving dynamics, the authors used the following measuring devices and equipment borrowed from Institute of Forensic Engineering of Brno University of Technology and Technical University of Graz (Differential GPS).

Fig. 1 shows equipment of testing vehicle visible from outside:

- PicDAQ: In particular, the following dynamic parameters of the vehicle were measured using this device: acceleration in three axes $(x, y, z)$; angular (yaw) velocity in three axes $(x, y, z)$; vehicle speed - GPS sensor; and vehicle yaw angle.

- Differential GPS: System of differential GPS ADMA by GeneSys used for measurement allows to measure position of the vehicle with accuracy of $\pm 1.0 \mathrm{~cm}$.

- Black Box: It is a system of cameras showing the interior and exterior of the vehicle. The cameras were placed with the focus on reading the digital speedometer of the vehicle, space in front of the vehicle (located on the windscreen), and the third brake light. The last (fourth) camera was positioned on the rear bumper of the vehicle in order to perform monitoring of the trajectory covered by the vehicle - according to marks on the roadway (control camera of the distance travelled).

- Light Gate: Light gate developed by Institute of Forensic Engineering of Brno University of Technology was placed in the beginning of the curve and measured the initial speed of testing vehicle with accuracy of $\pm 0.5 \mathrm{~km} / \mathrm{h}$. The results from light gate were verified by differential GPS. 


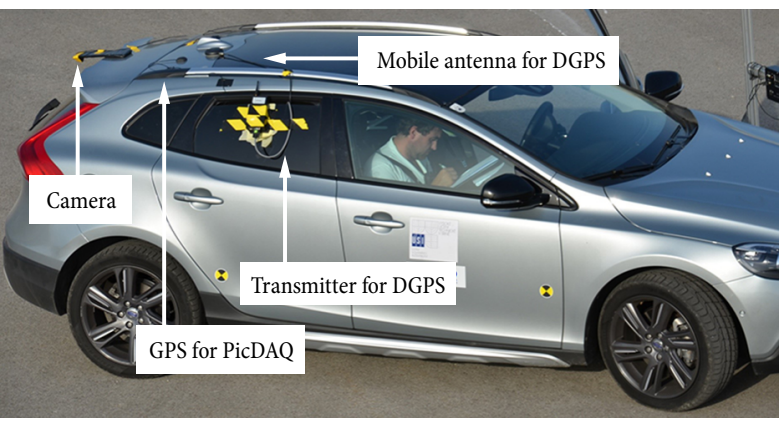

Fig. 1. External measurement equipment installation on the tested vehicle - Volvo V40 T5 AWD Cross Country

(Panáček 2015)

\subsection{Polygon}

All experimental measurements of dynamics parameters of the Volvo V40 T5 AWD Cross Country vehicle were carried out on a special test area - the polygon of DSD, an Austrian company. On the asphalt polygon surface in the area with dimensions of $40 \times 93 \mathrm{~m}$, there were three painted curves - radius: 30,40 and $50 \mathrm{~m}$.

A substantial quantity for analysis of the vehicle behaviour in the general spatial curve represents the coefficient of adhesion between the tyre and the road. In order to establish the value of the coefficient of adhesion in the longitudinal direction, the authors carried out, on the Volvo V40 T5 AWD Cross Country vehicle with the active assistance system DSTC in its normal mode, braking tests on the dry surface with the initial braking speeds of 50, 60 and $80 \mathrm{~km} / \mathrm{h}$. Braking tests of the Volvo V40 T5 AWD Cross Country vehicle on the dry polygon surface showed an achievable longitudinal vehicle deceleration in a range from 8.3 to $11.6 \mathrm{~m} / \mathrm{s}^{2}$, which corresponds approximately to the range of values of the adhesion coefficient in the longitudinal direction $\mu$ from 0.85 to 1.18 [-]. This range was has been calculated according to the formula:

$$
\mu=\frac{a}{g}
$$

where: $a$ - acceleration of vehicle in longitudinal direction $\left[\mathrm{m} / \mathrm{s}^{2}\right] ; g$ - gravitational acceleration $\left[\mathrm{m} / \mathrm{s}^{2}\right]$.

\section{Results}

Within the scope of experimental measurements carried out at the polygon of DSD in the area of the Austrian village of Allhaming, the authors conducted, in total, 53 evaluated drives and braking of the vehicle in curves.

The experimental measurements comprised, in total, 24 drives and braking of the Volvo V40 T5 AWD Cross Country vehicle in a curve with a radius of $30 \mathrm{~m}$, out of which 14 drives and braking with the DSTC assistance system were performed in the normal mode (DSTC ' $\mathrm{N}$ ') while the remaining 10 drives and braking were accomplished with the DSTC assistance system in the sport mode (DSTC 'S'). Experimental measurements of parameters of the vehicle driving dynamics - driving and braking in a curve with the radius of $30 \mathrm{~m}$ with the DSTC assistance system activated in the normal mode - the authors determined the range of values of attained lateral acceleration from 2.8 to $10.2 \mathrm{~m} / \mathrm{s}^{2}$ when driving at speeds of $52-62 \mathrm{~km} / \mathrm{h}$ and subsequently, as a consequence of braking in the curve from the speeds of $44-59 \mathrm{~km} / \mathrm{h}$, the range of values of the longitudinal deceleration from 3.5 to $9.6 \mathrm{~m} / \mathrm{s}^{2}$. When driving and braking in the curve with a radius of $30 \mathrm{~m}$ with the DSTC assistance system activated in the sport mode, the authors determined the range of values of attained lateral acceleration from 2.6 to $10.2 \mathrm{~m} / \mathrm{s}^{2}$ when driving through the curve at speeds of $47-59 \mathrm{~km} / \mathrm{h}$ and subsequently, due to braking in the curve from the speeds of $41-57 \mathrm{~km} / \mathrm{h}$, the range of the values of the longitudinal deceleration from 3.9 to $10.3 \mathrm{~m} / \mathrm{s}^{2}$. One of the driving tests is shown in the chart on Fig. 2. The testing vehicle entered the curve with radius of $30 \mathrm{~m}$ in speed of $59 \mathrm{~km} / \mathrm{h}$ and started to brake from the speed of $57 \mathrm{~km} / \mathrm{h}$. Average values of attained lateral and longitudinal acceleration in course of driving and braking in curve were both the same around $8.5 \mathrm{~m} / \mathrm{s}^{2}$.

Furthermore, the authors carried out, in total, 16 drives and braking of the Volvo V40 T5 AWD Cross Country vehicle in a curve with a radius of $40 \mathrm{~m}$, out of which 8 runs and braking with the DSTC assistance system were performed in the normal mode while the remaining 8 runs and braking were accomplished with the DSTC assistance system in the sport mode. Experi-

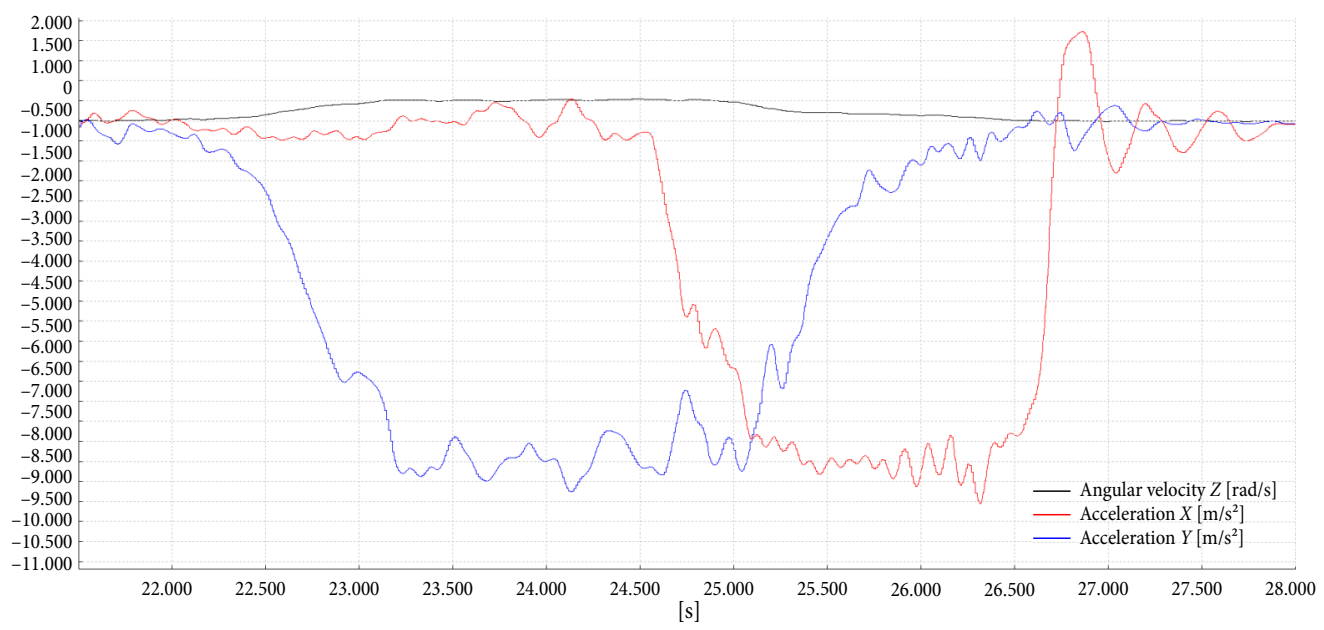

Fig. 2. Driving and braking of the Volvo V40 T5 AWD Cross Country vehicle in the curve of 30 m radius with the entering speed of $59 \mathrm{~km} / \mathrm{h}$, and speed at the beginning of braking reaching $57 \mathrm{~km} / \mathrm{h}$, DSTC sports mode (Exper. No 25) (Panáček 2015) 
mental measurements of parameters of the vehicle driving dynamics - driving and braking in a curve with the radius of $40 \mathrm{~m}$ with the DSTC assistance system activated in the normal mode - the authors determined the range of values of attained lateral acceleration from 3.7 to $10.1 \mathrm{~m} / \mathrm{s}^{2}$ when driving through the curve at speeds of $57-72 \mathrm{~km} / \mathrm{h}$ and subsequently, as a consequence of braking in the curve from the speeds of $57-69 \mathrm{~km} / \mathrm{h}$, they determined the range of the values of the longitudinal deceleration of 4.0 to $10.8 \mathrm{~m} / \mathrm{s}^{2}$. When driving and braking in the curve with a radius of $40 \mathrm{~m}$ with the DSTC assistance system activated in the sport mode, the authors determined the range of values of attained lateral acceleration from 4.8 to $10.0 \mathrm{~m} / \mathrm{s}^{2}$ when driving through the curve at speeds of $63-70 \mathrm{~km} / \mathrm{h}$ and subsequently, due to braking in the curve from the speeds of $60-67 \mathrm{~km} / \mathrm{h}$, the range of the values of the longitudinal deceleration from 6.0 to $10.1 \mathrm{~m} / \mathrm{s}^{2}$.

At the end of experimental measurements the authors performed, in total, 13 subsequently evaluated drives and braking of the Volvo V40 T5 AWD Cross Country vehicle in a curve with a radius of $50 \mathrm{~m}$, out of which 7 runs and braking with the DSTC assistance system were performed in the normal mode while the remaining 6 runs and braking were accomplished with the DSTC assistance system in the sport mode. Experimental measurements of parameters of the vehicle driving dynamics - driving and braking in a curve with the radius of $50 \mathrm{~m}$ with the DSTC assistance system activated in the normal mode - the authors determined the range of values of attained lateral acceleration from 5.0 to $10.4 \mathrm{~m} / \mathrm{s}^{2}$ when driving through the curve at speeds of $71-81 \mathrm{~km} / \mathrm{h}$ and subsequently, as a consequence of braking in the curve from the speeds of $68-74 \mathrm{~km} / \mathrm{h}$, they determined the range of the values of the longitudinal deceleration from 4.7 to $9.8 \mathrm{~m} / \mathrm{s}^{2}$. In case of radius of 50 $\mathrm{m}$ with the DSTC system in the sport mode, the authors determined the range of values of attained lateral acceleration from 5.5 to $9.8 \mathrm{~m} / \mathrm{s}^{2}$ when driving through the curve at speeds of $72-75 \mathrm{~km} / \mathrm{h}$ and subsequently, due to braking in the curve from the speeds of $66-72 \mathrm{~km} / \mathrm{h}$, the range of the values of the longitudinal deceleration from 3.5 to $9.9 \mathrm{~m} / \mathrm{s}^{2}$.

\section{Interpretation of Results and Discussion}

As regards the measured parameters of vehicle driving dynamics, Fig. 3 shows the plotted range of minimum and maximum lateral acceleration of the vehicle equipped with the DSTC assistance system depending on the speed. The space between the red and blue lines in the chart (Fig. 3) shows the achievable lateral acceleration values depending on the speed of a vehicle equipped with the DSTC assistance systems.

The completed experiments showed that a modern vehicle equipped with a stabilization system, AWD and good quality tyres could move, in the defined curves, with a relatively high value of the utilized coefficient of adhesion in the lateral direction. The vehicle equipped with a stabilization system can use the adhesion coefficient in the lateral direction considerably more than a vehicle without a stabilization system. Based on results of the experiments, the detected values of lateral acceleration of the vehicle with a stabilization system were used for the purpose of drafting Table, which according to the style of driving in relation of vehicle's limit speed in the specific curve assessed by the crew and also by an external observer, defines usable adhesion coefficient in the lateral direction. Ranges of adhesion coefficient for ride style description were calculated from the vehicle speed in the curve and corresponding curve radius and safety boundary corresponds to the limit speed in the curve.

The analysed driving experiments carried out at the DSD polygon also show that, in all experimental measurements of parameters of driving dynamics, yaw rate values of the Volvo V40 T5 AWD Cross Country vehicle equipped with the DSTC stabilization system ranged from 0.4 to $0.6 \mathrm{rad} / \mathrm{s}$. It is therefore obvious that the vehicle stability system ensured that during the driving experiments the vehicle did not get into the yaw rate values higher than $0.6 \mathrm{rad} / \mathrm{s}$.

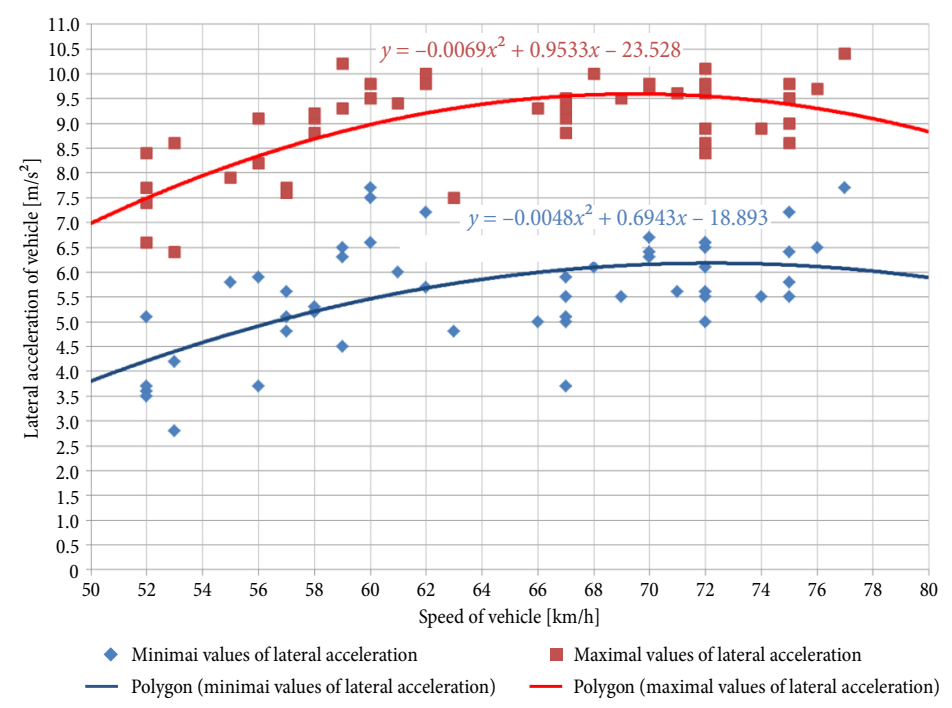

Fig. 3. Achievable lateral acceleration values depending on the speed of a Volvo V40 T5 AWD Cross Country vehicle equipped with the driving stability control system on dry asphalt surface (Panáček 2015) 
Table. The available values of the adhesion coefficient in the lateral direction according to driving style of the Volvo V40 T5 AWD Cross Country vehicle equipped with the driving dynamics stabilization system (Panáček 2015)

\begin{tabular}{|l|c|}
\hline \multicolumn{1}{|c|}{ Style of driving } & $\begin{array}{c}\text { Coefficient of adhesion } \\
\text { in the lateral direction }\end{array}$ \\
\hline Fast drive & from 0.50 to 0.60 \\
\hline Sporty ride & from 0.70 to 0.80 \\
\hline Critical ride & from 0.85 to 0.95 \\
\hline Safety boundary & 1.0 \\
\hline
\end{tabular}

Based on measurements several simulations with the help of simulating software for traffic accident reconstruction (PC-CRASH and Virtual CRASH) were made and the parameters of electronic stability model have been gained. Based on driving tests and linear used tyre model it is advised to consider yaw rate threshold values from 0.4 to $0.5 \mathrm{rad} / \mathrm{s}$, cycle time of $0.01 \mathrm{~s}$ and efficiency factor between 15 and $20 \%$ for settings in Virtual CRASH version 3.0 and yaw rate threshold value around $0.1 \mathrm{rad} / \mathrm{s}$, cycle time of $0.01 \mathrm{~s}$ and control factor 1.0 for settings in PC-CRASH version 9.1.

Based on measurements carried out during the longitudinal deceleration of the vehicle in the course of braking in individual curves, it is clear that the usable values of the maximal longitudinal deceleration achieved while braking in a curve approximately correspond to the values of maximal lateral acceleration attainment in the given curve; the adhesive ellipse substantially becomes the circle of adhesion. The experimental measurements revealed that the maximal usable adhesion coefficient in the lateral direction for modern vehicle with stability system is getting very close to the maximal coefficient of adhesion in the longitudinal direction.

\section{References}

Burg, H.; Moser, A. 2009. Handbuch Verkehrsunfallrekonstruktion: Unfallaufnahme, Fahrdynamik, Simulation. Vieweg+Teubner Verlag. 1032 S. (in German). http://doi.org/10.1007/978-3-8348-9974-3

Dell'Acqua, G. 2015. Modeling driver behavior by using the speed environment for two-lane rural roads, Transportation Research Record: Journal of the Transportation Research Board 2472: 83-90. http://doi.org/10.3141/2472-10

Heinrichs, B. E.; Allin, B. D.; Bowler, J. J.; Siegmund, G. P. 2004. Vehicle speed affects both pre-skid braking kinematics and average tire/roadway friction, Accident Analysis \& Prevention 36(5): 829-840.

http://doi.org/10.1016/j.aap.2003.08.002

Kim, J. 2009. Identification of lateral tyre force dynamics using an extended Kalman filter from experimental road test data, Control Engineering Practice 17(3): 357-367. http://doi.org/10.1016/j.conengprac.2008.08.002

Panáček, V. 2015. Problematika znalecké analýzy jízdy a brzdění vozidla $v$ obecném prostorovém oblouku při rychlostech vyšších než $50 \mathrm{~km} / \mathrm{h}$ : dizertační práce. Vysoké učení technické v Brně, Ústav soudního inženýrství. 187 s. (in Czech).
Ritchie, M. L.; McCoy, W. K.; Welde, W. L. 1968. A study of the relation between forward velocity and lateral acceleration in curves during normal driving, Human Factors: the Journal of the Human Factors and Ergonomics Society 10(3): 255-258.

Rudin-Brown, C.; Noy, Y. I. 2002. Investigation of behavioral adaptation to lane departure warnings, Transportation Research Record: Journal of the Transportation Research Board 1803: 30-37. http://doi.org/10.3141/1803-05

Wesemeier, D.; Isermann, R. 2009. Identification of vehicle parameters using stationary driving maneuvers, Control Engineering Practice 17(12): 1426-1431. http://doi.org/10.1016/j.conengprac.2008.10.008

Zhu, W.-X.; Zhang, L.-D. 2012. Friction coefficient and radius of curvature effects upon traffic flow on a curved road, Physica A: Statistical Mechanics and its Applications 391(20): 4597-4605. http://doi.org/10.1016/j.physa.2012.05.032 